\title{
The role of working memory capacity and knowledge access in text inference processing
}

\author{
MURRAY SINGER and KATHRYN F. M. RITCHOT \\ University of Manitoba, Winnipeg, Manitoba, Canada
}

\begin{abstract}
Individual differences in drawing bridging inferences during text comprehension were examined. We measured reader differences in working memory capacity, using the reading span task, and in access to relevant knowledge, using Potts and Peterson's (1985) integration task. The dependent measure of greatest concern was answer time about facts posited to validate the bridging inference. Reading span and access were negligibly correlated, an outcome that supports their independence. Answer times were lower both for high reading span and high-access readers. In addition, readers who were either high on both reader traits or low on both traits exhibited qualitatively different inference effects from the typical pattern. It is proposed that knowledge access during comprehension is facilitated by the extraction of integrated situation models from text and that it is individuals with efficient reading processes who can construct these models.
\end{abstract}

The focus on individual differences among readers is a growing trend in the study of language processes. This development stems, in large part, from landmark findings that individual differences in working memory capacity are correlated with standardized measures of comprehension (e.g., verbal SAT) and with readers' ability to resolve pronouns in comprehension and to answer questions about text (Daneman \& Carpenter, 1980). These results have prompted researchers to explore the involvement of working memory capacity in parsing (MacDonald, Just, \& Carpenter, 1992), lexical access (Miyake, Just, \& Carpenter, 1994), pronoun resolution (Daneman \& Carpenter, 1980 ), and inference processing (Dixon, Lefevre, \& Twilley, 1988; Masson \& Miller, 1983; Singer, Andrusiak, Reisdorf, \& Black, 1992; Whitney, Ritchie, \& Clark, 1991). One striking feature of this research has been the demonstration of qualitative and quantitative processing differences as a function of reader differences (Just \& Carpenter, 1992; MacDonald et al., 1992).

The reading span task (Daneman \& Carpenter, 1980, 1983) has been central to the involvement of working memory in language comprehension. In this task, the subject reads sentences in sets that appear in monotonically increasing order of the number of sentences. After each set, the subject reports the last word of each sentence. Daneman and Carpenter (1983) measured reading span

\footnotetext{
This research was supported by Grant OGP9800 from the Natural Sciences and Engineering Research Council of Canada to the first author. The data were presented at the meeting of the Psychonomic Society, St. Louis, November 1994. The authors are grateful to Warren Eaton for his suggestions concerning the design of this study. The authors would also like to thank Rob Zak and Dana Harkness for their assistance in the collection and the analysis of the data. Correspondence should be addressed to M. Singer, Department of Psychology, University of Manitoba, Winnipeg, MB, Canada R3T2N2 (e-mail: singer@bldgduff.lan 1. umanitoba.ca)
}

as the largest sentence set size for which the subject responds perfectly.

One focus of our research has been the "bridging inferences" that reconcile different parts of a message. The next section describes an analysis of bridging processes. The following two sections describe the relevance of working memory capacity and an additional reader characteristic to these processes.

\section{Validation of Bridging Inferences}

Bridging inferences serve to establish connections between the current sentence and preceding text. For the sequence, The spy quickly threw his report in the fire, The ashes floated up the chimney, detecting the causal relation between the two sentences results in the construction of the causal bridge that the first event caused the second (Black \& Bern, 1981; Singer \& Ferreira, 1983). Bridging processes are also likely to add propositions, derived from world knowledge, to the text representation. For the present example, the ideas that the report burned up, that it was made of paper, and that paper burns to ash might be added.

Bridging inferences specify the links among ostensively unrelated text ideas (Haviland \& Clark, 1974; Singer, 1980). Without such inferences, the coherence of most ordinary messages would be lost. Consistent with this observation, evidence stemming from on-line and memory measures indicates that bridging inferences are frequently drawn during reading (Bloom, Fletcher, van den Broek, Reitz, \& Shapiro, 1990; Keenan, Baillet, \& Brown, 1984; Myers, Shinjo, \& Duffy, 1987; Potts, Keenan, \& Golding, 1988; Singer \& Ferreira, 1983; Suh \& Trabasso, 1993). If reader deficiencies prohibited the computation of bridging inferences, the derivation of a coherent message representation would be impeded.

It has been proposed that drawing a text bridging inference includes a stage of "validation" (Singer \& Hall- 
dorson, 1996; Singer, Halldorson, Lear, \& Andrusiak, 1992; Singer, Revlin, \& Halldorson, 1990). This analysis can be explained with reference to Set 1 :

(1) a. Julie took an aspirin.

b. Her headache went away.

A thorough understanding of Sequence $1 \mathrm{a}-1 \mathrm{~b}$ involves the recognition that the first event motivated the second event. The validation model adds that before the reader accepts this bridging inference, it must be validated against world knowledge. It is proposed that, first, a "mediating" fact is derived from the text cause and outcome. Here, the mediating fact might take the form, "Aspirin relieves headaches." The mediating fact is then evaluated with reference to relevant knowledge. For the present example, world knowledge supports the mediating fact. As a result, the bridging inference has been validated.

The validation model has been evaluated with reference to sentence frames such as Set 2:

(2) a. Dorothy poured the bucket of water on the bonfire. The bonfire went out. (causal)

b. Dorothy placed the bucket of water by the bonfire. The bonfire went out. (temporal)

c. Does water extinguish fire?

The sentences of $2 a$ are causally related. Sequence $2 b$, in contrast, functions as a temporal control. Question $2 \mathrm{c}$ probes the world knowledge posited to validate the bridging inference underlying $2 \mathrm{a}$. Consistent with this analysis, people answer $2 \mathrm{c}$ more quickly after reading $2 \mathrm{a}$ than after $2 b$ (Singer, 1993; Singer, Halldorson, et al., 1992). This result is not due to extra priming of the question by the words of $2 \mathrm{a}$, because the answer time difference is abolished when subjects answer Question $2 \mathrm{c}$ after reading only the first sentence of either $2 \mathrm{a}$ or $2 \mathrm{~b}$ (Singer, Halldorson, et al., 1992, Experiment 1). The possibility that the answer time difference results from the spillover of processing from the sequence to the question is refuted by the finding that the difference persists when the questions are delayed until the end of a brief story (Singer, Halldorson, et al., 1992, Experiment 2). A third alternative explanation of the finding is that it reflects a check of the question against its textual context at retrieval time. However, Singer and Halldorson (1996, Experiment 5) reported that, after subjects have read a series of passages, the validating knowledge (e.g., water extinguishes fire) is primed more by text outcomes in the causal condition than in the temporal condition. Priming effects of this sort are interpreted as diagnosing text encoding effects rather than context checking (McKoon \& Ratcliff, 1988).

\section{Working Memory and Language Comprehension}

Working memory is viewed as the workspace for ongoing mental computations and the storage of the products of those processes (Baddeley, 1986; Baddeley \& Hitch, 1974; Just \& Carpenter, 1992). The antecedent construct of short-term memory, in contrast, highlighted the storage capacity available for recently encountered ideas (Miller, 1956). The contribution of working memory to language processing is strongly indicated. That is, language comprehension, whether listening or reading, requires the multilevel encoding of strings of words (Carpenter \& Just, 1989; van Dijk \& Kintsch, 1983). Working memory capacity enables the execution of complex processes, as well as the retention of those partial products of comprehension that permit the processes to run to completion.

The success of reading span (Daneman \& Carpenter, 1980) as a measure of working memory capacity turns on the strength of its relation to standardized and laboratory measures of comprehension, as discussed at the outset. Its extensive use, however, has generated controversies that are pertinent to the present concerns. First, the relationship between reading span and comprehension might reflect either the total capacity of activation that may be allocated to comprehension or the efficiency of the reader's language processes (Just \& Carpenter, 1992). Just and Carpenter described activation capacity using a metaphor to an energy source that may be applied to one or more tasks and that some individuals have more of than do others. Either total capacity or greater processing efficiency would permit the retention of more sentence-final words in the reading span task. However, studies of the relationship between reading span and comprehension have not been designed to distinguish these alternatives.

Second, if the relationship between reading span and comprehension reflects total capacity rather than process efficiency, this capacity might be either specific to the language realm or domain-free. Investigations of this problem have compared reading span with other complex span tasks - particularly, mathematical ones. Studies favoring the language-specific interpretation have revealed that comprehension measures are more strongly related to reading span than to math span (Baddeley, Logie, NimmoSmith, \& Brereton, 1985) and that reading span is a significant predictor of comprehension after the contribution of math span has been partialed out (Daneman \& Tardif, 1987).

Studies supporting the domain-free character of working memory resources have presented evidence of similar patterns of relation between comprehension and span tasks of different domains (Engle, Cantor, \& Carullo, 1992; Turner \& Engle, 1989; Yuill, Oakhill, \& Parkin, 1989). In this regard, Turner and Engle created span tasks by crossing processing domain by recall domain. In the mathprocessing/verbal-recall task, for example, stimuli such as " $9 / 3-2=5$; LAMP" were presented. The subject had to verify the equation, and retain the word for report at the end of a series of stimuli. Turner and Engle reported that comprehension was equally strongly related to the language operation and math operation tasks. In addition, when the difficulty of these tasks was varied, the two operation categories yielded highly similar complex patterns of relation to comprehension. Working against the domain-free hypothesis, however, was the result that subjects' performance predicted comprehension better when they had to report words (e.g., lamp) than when they had to report numbers (see Turner \& Engle, 1989, pp. 151-152, for a discussion). 
Thus, evidence concerning the working memory capacity versus process efficiency view of the reading span task and concerning the domain-specificity of working memory capacity is not conclusive. In this study, we adopt a working hypothesis that individuals differ in their resources of domain-free activation that may be allocated to complex tasks. This view is founded on the notion that working memory capacity indeed contributes to comprehension and that language processing efficiency is captured by another reader characteristic-namely, access to relevant knowledge. This proposal will be justified with reference to the results of the present experiment and to an analysis of the mechanisms of knowledge access presented in the Discussion section.

\section{Knowledge Access and Comprehension}

The second characteristic that was inspected was the reader's access to relevant knowledge during comprehension. Access to world knowledge is essential for the computation of bridging inferences. In particular, the validation of a bridging inference depends on the reader's retrieval of the knowledge that validates the idea mediating the current sentence and its antecedent.

Although this study emphasizes bridging inferences, we adopt a view of access that encompasses retrieval both from general knowledge structures and from text (Singer, Andrusiak, et al., 1992). Efficient access from text, to cite one example, enables the retrieval of antecedent information, such as that needed to resolve a pronoun. This analysis of access is congruous with McKoon and Ratcliff's (1992) availability criterion of inference processing. They proposed that one sufficient criterion of inference computation is the ready availability, from general knowledge or text memory, of information that supports the inference (cf. Singer, Graesser, \& Trabasso, 1994). McKoon and Ratcliff did not address the issue of individual differences in ease of availability.

Further to the proposal that access refers to retrieval from text as well as general knowledge, Gernsbacher (1990) proposed that a central "marker" of reading skill is that strong readers maintain more reliable access to text structures than do weak readers. In one study, Gernsbacher's subjects read stories and then viewed test sentences either identical to or grammatically changed from ones in the stories. The tests were presented immediately after each half-story or after the subjects wrote a summary after reading the full story. Skilled readers outperformed less skilled readers in both the immediate and the delayed tests, but their advantage was significantly diminished in the delayed condition. Gernsbacher concluded that the large difference in the immediate test resulted from the less skilled readers' quick loss of access to text information.

Long, Oppy, and Seely (1994) also associated skill differences among readers with ease of access to antecedent text structures. They reported that skilled and less skilled readers exhibited similar temporal patterns of activation of appropriate word senses in the comprehension of passages, as indexed by the subjects' lexical decisions. How- ever, their data also showed that the judgment times of the skilled readers plateaued after the advantage of appropriate senses over inappropriate senses emerged. In contrast, the judgment times of less skilled readers became steadily slower after this point. Long et al. abolished the steady slowdown of the low-skill readers' responses by introducing a comprehension question after each passage. They proposed that the less skilled readers performed the lexical decisions by means of a context check between the test item and the passage but that their access to the passage was poor. The postpassage questions were argued to highlight the comprehension aspect of the task and so increase the accessibility of the text representation.

Impaired access to relevant text structures can hinder the text processing of average readers. Glanzer and Nolan (1986) disrupted reading with intermittent recognition tests. When the test items probed the topic of a prior paragraph, reading time for the next sentence was longer than when the item addressed the topic of the current paragraph. In the terminology of Gernsbacher (1990), the prior-topic test items shifted the readers' attention away from the current structure. Reading the successive sentence then required a time-consuming reinstatement of that structure.

To measure the access trait, we used the integration task of Potts and Peterson (1985). The task presents brief paragraphs that interrelate familiar and nonsense concepts. One example is presented in Table 1. Each paragraph is studied, one sentence at a time, in a self-paced manner, and is followed by a series of questions. Of greatest interest, for the present purposes, are questions such as Is a TOC larger than a CAZ? This question can be answered correctly only if the reader accesses the knowledge that a pony is larger than a beaver.

The access scale has been shown to predict the integration of text and world knowledge in two contexts. First, Potts and Peterson's (1985) subjects read passages describing unfamiliar concepts, such as the takahe, a bird that lives in New Zealand. After reading, stronger prim-

Table 1

Sample Paragraph and Questions From Integration Task

Paragraph

A JAL is larger than a TOC.
A beaver is larger than a CAZ.
A TOC is larger than a pony.
True Test Questions
Access
A TOC is larger than a beaver.
A pony is larger than a CAZ.
Memory
A JAL is larger than a TOC.
Inference
A JAL is larger than a pony.
Real
A pony is larger than a beaver.

Note-From "Individual Differences in Bridging Inference Processes," by M. Singer, P. Andrusiak, P. Reisdorf, and N. L. Black, 1992, Memory \& Cognition, 20, p. 540 . Copyright 1992 by The Psychonomic Society, Inc. 
ing effects between the new term and its category name were measured for high-access subjects than for lowaccess ones.

Second, Singer, Andrusiak, et al. (1992) proposed that the access scale would predict success in computing bridging inferences during reading. Their subjects read brief stories that included sequences such as The spy quickly threw his report in the fire, The ashes floated up the chimney. The critical sentences were either adjacent (near) in the text or separated by two intervening sentences (far). After each story, the subjects answered questions, including ones that probed part of the bridging inference, such as Did the report burn up? The main finding was that both reading span and access were significant predictors of bridging inference accuracy, but only in the far condition. The lack of impact of individual differences in the near inference condition is consistent with the relative ease of detecting the connection between adjacent sentences.

\section{Overview of the Experiment}

The central hypothesis of this study was that the validation of bridging inferences is independently influenced by reading span and access. This relation was assessed with reference to materials such as Set 3:

(3) a. Valerie left early for the birthday party. (motive)

$a^{\prime}$. Valerie left the birthday party early. (control)

b. She spent an hour shopping at the mall.

c. Do birthday parties involve presents?

Set 3 was viewed in either the motive condition $(3 a-3 b)$ or the control condition $\left(3 a^{\prime}-3 b\right)$. According to the validation analysis, the motive sequence should activate the reader's knowledge about bringing presents to birthday parties. The control sequence, in contrast, does not suggest as specific a causal relation. Singer and Halldorson (1996) reported that Question $3 \mathrm{c}$ is answered more quickly in the motive condition than in the control condition.

The present materials were manipulated in another manner. Each set comprised either two sentences, or the same two sentences with four intervening sentences, as illustrated in Set 4:

(4) a. Valerie left early for the birthday party. (motive)

$a^{\prime}$. Valerie left the birthday party early. (control)

b. She checked the contents of her purse.

c. She backed out of the driveway.

d. She headed north on the freeway.

e. She exited at Antelope Drive.

f. She spent an hour shopping at the mall.

g. Do birthday parties involve presents?

To summarize, the study was designed to inspect the reader characteristics of reading span and access, as well as the manipulated variables of relation (motive vs. control) and distance. We distinguished two competing hypotheses about the impact of reading span and access on performance. First, the compensatory hypothesis is a disjunctive position: It states that being high in either working memory capacity or one's access to the knowledge relevant to comprehension will result in successful validation. According to this analysis, only the low-span, low- access readers should fail to bridge the motive sequences. It is most likely that this failure would be restricted to the far inference condition. In the near condition, the motive antecedent should be available for all readers. The absence of a validation effect only in the far inference condition for readers low in both reading span and access would produce a reading span $\times$ access $\times$ relation $\times$ distance interaction.

The second hypothesis posits qualitative differences among readers of different skill levels (Just \& Carpenter, 1992). These differences could take too many forms to permit the association of one particular prediction with the qualitative hypothesis. It is noted, however, that the compensatory hypothesis assumes that answer time for validating questions is uniformly slow in the control condition. That is, fluctuation in the size of the validation effect would result solely from variation, among the reader groups, in the motive condition answer times. An alternative, consistent with the qualitative hypothesis, is that both motive and control answer time may vary among reader groups.

Several differences between the present study and that of Singer, Andrusiak, et al. (1992) deserve mention. First, we probed the relevant knowledge posited to validate bridging inferences, whereas Singer, Andrusiak, et al. (1992) examined the inferred propositions that bridge text ideas. Second, the present study emphasized inference judgment time, a more convincing index of on-line comprehension than the inference accuracy measure highlighted by Singer, Andrusiak, et al. (1992). A methodological difference was that we explored these issues in the framework of a factorial design for the first time. This approach sacrifices much of the variability of the reading span and access measures. However, pilot data collected in our laboratory indicated that subjects are distributed quite evenly across the four cells obtained by applying median splits to the individual differences measures. The likelihood of measuring relatively clear effects concerning these issues in a factorial design was considered a worthwhile goal (e.g., Lee-Sammons \& Whitney, 1991; Long et al., 1994; Miyake et al., 1994).

\section{METHOD}

\section{Subjects}

The subjects were 203 students of introductory psychology at the University of Manitoba who participated for credit toward a course requirement. All of the subjects were native speakers of English.

\section{Materials}

Reading span. The reading span task materials were those developed by Singer, Andrusiak, et al. (1992), following the general plan of Daneman and Carpenter (1980). A total of 46 sentences, 10-14 words in length, appeared in 14 sets. In particular, there were five sets of two sentences, and three sets each of three, four, and five sentences. The sentences were randomly sampled from a pool of 100 unrelated sentences, which in turn had been selected randomly from a variety of reading sources on different topics.

For each sentence set, there was one cloze item (e.g., Masson \& Miller, 1983). The cloze item referred to one randomly selected sentence from its set. In the cloze item, two randomly designated 
content words were deleted and replaced with blank spaces. Table 2 shows a sentence set of Size 4 and its cloze item.

Integration task. The materials of the integration task were six paragraphs of three sentences, each with an accompanying set of 18 test items (Potts \& Peterson, 1985). One set of materials was shown in Table 1. The paragraph consisted of three sentences that related three nonsense concepts and two real concepts. Each paragraph was presented to all subjects in a single random order. By relating the three sentences of a paragraph, the subjects could derive a linear ordering, such as JAL $>$ TOC $>$ pony $>$ beaver $>$ CAZ (see Table 1).

For each paragraph, there were access, memory, inference, and real test items. Table 1 presents test items of each type for the sample paragraph. The access items required the combination of text ideas and general knowledge. That is, to judge the test item $A T O C$ is larger than a beaver, the subject must integrate the newly learned knowledge that "A TOC is larger than a pony" with the knowledge that a pony is larger than a beaver. The memory items related two concepts, real or nonsense, that corresponded to a paragraph sentence. The inference test items could be answered correctly without reference to general knowledge. For example, having read $A J A L$ is larger than a TOC and $A T O C$ is larger than a pony, an inference test item might state, $A J A L$ is larger than a pony. Finally, the real test items related the two real concepts discussed in the paragraph.

There were nine true test items for each paragraph, consisting of four access, one inference, one real, and three memory items. Nine additional false items were constructed by reversing the terms of the true items. The test items of each passage were presented in a single random order. The access scale was based on the four true and four false items for each paragraph.

Inference validation task. The inference task materials were motive inference passages and accompanying questions constructed by Singer and Halldorson (1996). There were 16 experimental passages, 40 filler passages, and 8 practice passages, yielding a total of 64 . The experimental passages were each based on frames such as Sets 3 and 4 , considered earlier. Set 3 is repeated here.

(3) a. Valerie left early for the birthday party. (motive)

$a^{\prime}$. Valerie left the birthday party early. (control)

b. She spent an hour shopping at the mall.

c. Do birthday parties involve presents?

These frames were used to manipulate the variables of relation and distance. Each experimental passage included either the motive antecedent, such as $3 \mathrm{a}$, or the control antecedent, $3 \mathrm{a}^{\prime}$. Second, the antecedent and outcome were either adjacent in the text (near) or separated by four intervening sentences (far). For the experimental passages, the question probed the general knowledge posited to be relevant to validating the bridging inference.

The 40 filler passages all presented ideas similar to those of the experimental materials. Twenty-four filler passages were followed by questions about their details, 12 each with the answers "yes" and

Table 2

Sample Sentence Set From the Reading Span Task

\section{Sentences}

After the storm had subsided we broke camp and departed.

Many students do not believe that homework is a good idea

The one great stumbling block was the lack of capital.

The following day the patient asked for a bedside telephone.

Correct Answer

departed idea capital telephone (in any order)

Cloze Item

The one great block was the lack of

Note-From "Individual Differences in Bridging Inference Processes," by M. Singer, P. Andrusiak, P. Reisdorf, and N. L. Black, 1992, Memory \& Cognition, 20, p. 542. Copyright 1992 by The Psychonomic Society, Inc. "no." These items were designed to induce the subject to attend to the content of the passages. The remaining 16 filler passages were followed by questions about relevant knowledge and had the answer "no." These items were intended to discourage the subjects from automatically responding "yes" whenever they encountered a question about world knowledge. Across the experimental and filler passages, the subjects encountered equal numbers of items with the correct answers "yes" and "no," for questions both about pertinent knowledge and about passage details.

Set 5 illustrates the filler items. For example, for the Filler Sequence $5 \mathrm{a}-5 \mathrm{~b}$, Questions $5 \mathrm{c}, 5 \mathrm{~d}$, and 5e illustrate the specific detailyes, specific detail-no, and general knowledge-no questions, respectively.

(5) a. Grace wanted to learn how to knit complex patterns.

b. She registered for a course.

c. Did Grace want to learn to knit? (specific-yes)

d. Did Grace want to learn to skate? (specific-no)

e. Are courses taught by the pupil? (general knowledge-no)

Each filler passage was followed by a single question. Set 5 shows three questions for the purposes of illustration only. Like the experimental items, half of the filler items included four intervening sentences between the antecedent and outcome sentences, and half did not.

Four counterbalanced lists were constructed from the experimental and filler materials. For the first list, each item was randomly assigned to list position. The experimental sets were randomly assigned in equal numbers to one of the four conditions, representing the crossing of relation and distance. This assignment was subject to the constraint that each half of the list include half of the items in each condition. Then, the other three lists were obtained by cycling the experimental sets across conditions, using a Latin-square procedure. No more than three consecutive items could represent any condition. Half of each type of filler item likewise appeared in each half of each list.

Finally, the lists began with eight practice items. There were two practice items each for the forms of the experimental, specific-yes, specific-no, and general knowledge-no items.

\section{Procedure}

Reading span. Reading span was measured in the first of two sessions. Testing was performed with groups of $4-16$ subjects, using a computerized technique. The subjects were tested at separate computer stations. At the outset of each trial, the message "Next Trial" appeared in the middle of the screen. The subject pressed the space bar to indicate readiness. A fixation point appeared for $0.5 \mathrm{sec}$. Then, the sentences of the current trial were displayed, one after the other, for $8 \mathrm{sec}$ each. After the last sentence of a set, the message "Write end words" appeared for $12 \mathrm{sec}$. During this interval, the subject wrote the final words of the sentences of the current set on an answer form. At the end of this period, a tone sounded, and the cloze item for the current set was displayed for $12 \mathrm{sec}$. The subject wrote the missing words of the cloze item on the answer form. At the end of the cloze interval, the tone sounded again. The message "Next trial" appeared for $1 \mathrm{sec}$, and the next sentence set was displayed.

Integration task. Session 2, comprising the integration task and the inference validation task, took place 1 week after Session 1 . The subjects were again tested in groups of 4-16.

The integration task was performed first. To initiate each trial, the participants pressed the space bar on the keyboard when they saw the message, "Press SPACE when READY." The letter X was presented as a fixation point for $0.5 \mathrm{sec}$, followed by the entire threesentence passage. The subject studied the passage for as long as was desired and then pressed the "Ready" bar again. After a 2.5-sec interval, the message "TEST ITEMS" was displayed for $1 \mathrm{sec}$. On each test trial, a fixation point was presented for $0.5 \mathrm{sec}$, followed by the test item. The subject had $5 \mathrm{sec}$ in which to respond "yes" or "no." Each subject was randomly assigned to use the computer keys " $\mathrm{x}$ " for yes and "." for no, or vice versa. 
After the last test item of a trial, there was an interval of $6 \mathrm{sec}$ Then, the message "Press SPACE when READY" initiated the next trial. The first of the six trials constituted practice. Practice was not explicitly distinguished for the subject.

Inference validation task. On each trial of the inference task, a fixation point appeared on the screen for $0.5 \mathrm{sec}$. Then, the subjects read the two- or six-sentence passage, one sentence at a time, in a self-paced fashion. They pressed the space bar to indicate that they understood the current sentence. The last sentence of a passage was followed by a 2.5 -sec interval. The fixation point reappeared for $0.5 \mathrm{sec}$, followed by the test question. The subject had $5 \mathrm{sec}$ to answer the question by pressing the "yes" or "no" key. If no response was registered in the allotted time, the subject was charged with an incorrect answer. There was an interval of $3 \mathrm{sec}$ between trials. Finally, there was a $40-\mathrm{sec}$ rest period halfway through the experimental part of the list--that is, after the 28 th experimental trial or the 36th trial including practice.

All responses and response times were recorded automatically by the computers. Reading time was measured to the nearest centisecond, and answer time was measured to millisecond accuracy.

\section{RESULTS}

Of the 203 subjects, 11 either did not return after 1 week or otherwise generated incomplete data sets. Results are reported for the remaining 192 subjects. Table 3 presents descriptive statistics for the dependent variables of interest. Two correlations involving reading span are of note. First, the correlation between reading span and access was $r=.07$, a value that is consistent with the independence of the two measures. Second, reading span correlated $r=.28$ with cloze task performance $(p<.01)$. This discourages the possibility that cloze task performance was traded off against the encoding of the sentencefinal words in the reading span task. Both of these correlational values are in close agreement with those observed by Singer, Andrusiak, et al. (1992).

Table 4 shows that all of the correlations among the components of the integration task reached significance. Knowledge about the relation among the real terms, such as pony and beaver, should not, in theory, contribute to performance for the memory and the inference items. However, consistent with the pattern previously detected (Potts \& Peterson, 1985; Singer, Andrusiak, et al., 1992), the mean of the correlations between the real items and the memory and inference components was .42 , compared with a mean of .69 for the other four correlations of Table 4. Accordingly, the profile of integration task correlations was comparable to those measured in previous investigations.

Table 3 Descriptive Statistics $(n=192)$

\begin{tabular}{lcc}
\hline Measure & $M$ & $S D$ \\
\hline Reading span (\%) & 76.6 & 11.9 \\
Integration task (\%) & & \\
Access & 79.6 & 18.7 \\
Memory & 83.4 & 15.0 \\
Inference & 85.0 & 17.3 \\
Real & 86.6 & 17.4 \\
Cloze (\%) & 41.1 & 15.3 \\
\hline
\end{tabular}

Table 4

Correlation Matrix for the Integration Task

\begin{tabular}{lccc}
\hline Predictor & Access & Memory & Inference \\
\hline Access & & & \\
Memory & .64 & & \\
Inference & .75 & .71 & \\
Real & .64 & .37 & .45 \\
\hline
\end{tabular}

Note-All $p s<.01$.

Median splits were used to categorize the subjects on the reading span and access scales. Low-span readers were those with scores of up to $76 \%$ on the reading span task. Low-access readers were correct on up to $85 \%$ of the access items. Table 6 shows that these values yielded appreciable numbers of subjects in the four reader categories.

The mean reading times of the outcome sentences in the inference validation task, to centisecond accuracy, are shown in Table 5. An analysis of variance (ANOVA) was applied to these scores, alternately treating subjects and items as the random variable. A significance criterion of $\alpha=.05$ is used throughout, unless otherwise indicated.

The ANOVA revealed only two effects of substance. First, the target sentences were read $15 \mathrm{csec}$ faster by high-reading-span subjects than by low-span subjects $\left[F_{1}(1,176)=6.97, M S_{\mathrm{e}}=7,914 ; F_{2}(1,15)=106.0\right.$, $\left.M S_{\mathrm{e}}=365.5\right]$. Second, reading time was $9 \mathrm{csec}$ shorter in the motive condition than in the control condition $\left[F_{1}(1,176)=14.9, M S_{\mathrm{e}}=1,108 ; F_{2}(1,15)=10.5, M S_{\mathrm{e}}=\right.$ 513.2]. In addition, the subjects random analysis revealed interactions of access $\times$ list $\left[F_{1}(1,176)=10.3, M S_{\mathrm{e}}=\right.$ $1,108]$ and relation $\times$ access $\times$ list $\left[F_{1}(1,176)=10.8\right.$, $\left.M S_{\mathrm{e}}=1,309\right]$.

The mean correct answer times and accompanying error rates for the inference task are shown in Table 6. An ANOVA using the same design as the reading time analysis revealed that each variable except list yielded a main effect. Answer time was $107 \mathrm{msec}$ shorter for highreading-span subjects than for low-span subjects $\left[F_{1}(1,176)\right.$ $\left.=4.34, M S_{\mathrm{e}}=545,664 ; F_{2}(1,15)=32.9, M S_{\mathrm{e}}=32,990\right]$. High-access readers answered $144 \mathrm{msec}$ faster than did low-access readers $\left[F_{1}(1,176)=3.80, M S_{\mathrm{e}}=545,664\right.$; $\left.F_{2}(1,15)=84.0, M S_{\mathrm{e}}=16,123\right]$. Answer time was $152 \mathrm{msec}$ shorter in the motive condition than in the control condition $\left[F_{1}(1,176)=74.1, M S_{\mathrm{e}}=60,386\right.$; $\left.F_{2}(1,15)=10.8, M S_{\mathrm{e}}=132,293\right]$. Finally, the subjects responded $76 \mathrm{msec}$ faster in the near condition than in the far condition $\left[F_{1}(1,176)=17.1, M S_{\mathrm{e}}=51,047\right.$; $\left.F_{2}(1,15)=2.80, M S_{\mathrm{e}}=129,520\right]$. The last effect was only marginally significant in the items random analysis ( $p=$ $.12)$ or with the defensible application of a one-tailed test $(p=.06)$.

There were two interactions of theoretical interest. The relation $\times$ reading span $\times$ access interaction was significant $\left[F_{1}(1,176)=7.28, M S_{\mathrm{e}}=56,304 ; F_{2}(1,15)=8.07\right.$, $\left.M S_{\mathrm{e}}=11,640\right]$, as was the distance $\times$ reading span $\times$ access interaction $\left[F_{1}(1,176)=5.12, M S_{\mathrm{e}}=309,105\right.$; $\left.F_{2}(1,15)=18.9, M S_{\mathrm{e}}=5,813\right]$. Tables 7 and 8 reveal that these interactions had similar forms. In particular, it was 
Table 5

Mean Reading Times (in Centiseconds) for the Outcome Sentences as a Function of Relation, Distance, Reading Span, and Access

\begin{tabular}{ccccccc}
\hline \multirow{2}{*}{ Reading Span } & & \multicolumn{2}{c}{ Near } & & \multicolumn{2}{c}{ Far } \\
\cline { 3 - 4 } \cline { 6 - 7 } \cline { 5 - 6 } High & Access & Motive & Control & & Motive & Control \\
\cline { 6 - 7 } & High & 176 & 189 & & 179 & 186 \\
& Low & 179 & 195 & & 185 & 196 \\
& High & 209 & 215 & & 199 & 210 \\
& Low & 190 & 200 & & 196 & 197 \\
\hline
\end{tabular}

predominantly those readers who were "heterogeneous" in their reading measures who generated sizable effects of relation and of distance - that is, the subjects who were high on one reader variable and low on the other. The "homogeneous" readers (high on both measures or low on both measures) yielded smaller effects. In fact, the interactions under consideration diagnose that the effects were significantly larger for the heterogeneous subjects than for the homogeneous subjects. In addition to the latter interactions, the reading span $\times$ access effect reached significance in the items random analysis only $\left[F_{2}(1,15)=\right.$ $\left.7.05, M S_{\mathrm{e}}=8,968\right]$.

In the subjects random analysis, there were 16 effects that included the list variable. Only 3 of these reached significance [relation $\times$ list, $F_{1}(1,176)=26.0, M S_{\mathrm{e}}=$ 56,304; distance $\times$ list, $F_{1}(1,176)=11.1, M S_{\mathrm{e}}=60,386$; relation $\times$ distance $\times$ list, $F_{1}(1,176)=14.8, M S_{\mathrm{e}}=$ 73,703 ]. These interactions occurred because the lists were not equated on such features as sentence and question length, word frequency, and number of different arguments. What is important is that the lists were counterbalanced in a manner that ensures that the comparisons among the four relation $\times$ distance conditions were based on identical materials. For this reason, no theoretical importance is assigned to the list interactions (Singer, Halldorson, et al., 1992).

Although different numbers of intervening sentences had previously been inspected in comparable experiments (Singer \& Halldorson, 1996), this is the first time that distance was manipulated within a single experiment of this sort. It is instructive that the control answer times exceeded the motive answer times by the similar values of $142 \mathrm{msec}$ in the near condition and $151 \mathrm{msec}$ in the far condition. The relation $\times$ distance interaction did not approach significance $(F \mathrm{~s}<1)$.

The mean error rate on experimental trials was $2.5 \%$. High-access subjects made fewer errors $(1.5 \%)$ than did low-access subjects $(3.5 \%)\left[F_{1}(1,176)=4.81, M S_{\mathrm{e}}=\right.$ $\left.120.7 ; F_{2}(1,15)=5.74, M S_{\mathrm{e}}=18.7\right]$. The only other significant effects in the error ANOVA were the reading span $\times$ access $\times$ relation $\times$ distance $\times$ list interaction in the subjects random analysis $\left[F_{1}(3,176)=3.33, M S_{\mathrm{e}}=\right.$ $50.7]$ and the access effect in the subjects random analysis $\left[F_{1}(1,15)=16.9, M S_{\mathrm{e}}=11.6\right]$.

\section{DISCUSSION}

We will first inspect the result patterns of the experiment and then address the contribution of working memory capacity and knowledge access to comprehension.

\section{Interpretation of the Results}

Two features of the results showed reading span and access to be independent of one another. First, the correlation between these two variables was only $r=.07$. Second, and consistent with the latter observation, median splits on reading span and access yielded comparable numbers of participants in the four resulting categories. The independence of reading span and access is central to the proposal that these variables reflect different features of the reader.

The intercorrelations among the subscales of the integration task provide an index of the validity of the access measure. As should be the case, the correlations between the real scale and the memory and inference scales, although significant, were lower than the other four intercorrelations. In some previous studies, these smaller correlations did not reach significance (Potts \& Peterson, 1985; Singer, Andrusiak, et al., 1992).

The answer time main effects of relation, distance, reading span, and access were all in the expected directions. The relation main effect lends further support to the validation analysis. As discussed earlier, that analysis asserts that the knowledge queried by the experimental questions is invoked in the comprehension of the motive sequences, but not for the control sequences.

The main effects were complemented by the interactions of relation $\times$ reading span $\times$ access and of distance $\times$ reading span $\times$ access. Of the compensatory and qualitative hypotheses, these interactions are more consistent with the qualitative view. In particular, the subjects who achieved high scores on exactly one of the reader characteristics exhibited larger effects than did those who were homogeneously high or low.

Table 6

Mean Correct Answer Times (in Milliseconds) and Error Rates as a Function of Relation, Distance, Reading Span, and Access

\begin{tabular}{|c|c|c|c|c|c|c|c|c|c|c|}
\hline \multirow[b]{3}{*}{ Reading Span } & \multirow[b]{3}{*}{ Access } & \multirow[b]{3}{*}{$n$} & \multicolumn{4}{|c|}{ Near } & \multicolumn{4}{|c|}{ Far } \\
\hline & & & \multicolumn{2}{|c|}{ Motive } & \multicolumn{2}{|c|}{ Control } & \multicolumn{2}{|c|}{ Motive } & \multicolumn{2}{|c|}{ Control } \\
\hline & & & $M$ & Error Rate & $M$ & Error Rate & $M$ & Error Rate & $M$ & Error Rate \\
\hline \multirow[t]{2}{*}{ High } & High & 50 & 1,757 & .01 & 1,849 & .01 & 1,786 & .01 & 1,947 & .01 \\
\hline & Low & 49 & 1,872 & .00 & 2,089 & .02 & 1,964 & .03 & 2,243 & .05 \\
\hline \multirow[t]{2}{*}{ Low } & High & 38 & 1,859 & .04 & 2,053 & .00 & 1,987 & .00 & 2,128 & .00 \\
\hline & Low & 55 & 1,998 & .03 & 2,120 & .03 & 2,061 & .01 & 2,101 & .06 \\
\hline
\end{tabular}


Table 7

Relation $\times$ Reading Span $\times$ Access Interaction in Answer Times (in Milliseconds)

\begin{tabular}{ccccc}
\hline & & \multicolumn{2}{c}{ Relation } & \\
\cline { 3 - 4 } Reading Span & Access & Motive & Control & Difference \\
\hline \multirow{2}{*}{ High } & High & 1,771 & 1,848 & $77^{*}$ \\
& Low & 1,918 & 2,166 & $248^{*}$ \\
\multirow{2}{*}{ Low } & High & 1,923 & 2,090 & $167^{*}$ \\
& Low & 2,029 & 2,110 & $81^{*}$ \\
\hline
\end{tabular}

${ }^{*} p<.05$, experimentwise.

Table 8

Distance $\times$ Reading Span $\times$ Access Interaction in Answer Times (in Milliseconds)

\begin{tabular}{ccccc}
\hline & & \multicolumn{2}{c}{ Distance } & \\
\cline { 3 - 4 } Reading Span & Access & Near & Far & Difference \\
\hline High & High & 1,803 & 1,867 & 64 \\
& Low & 1,980 & 2,104 & $124^{*}$ \\
Low & High & 1,956 & 2,058 & $102^{*}$ \\
& Low & 2,059 & 2,081 & 22 \\
\hline
\end{tabular}

${ }^{*} p<.05$, experimentwise.

Consider, for example, the interaction involving the relation effect (Table 7). According to a strict reading of the validation analysis, control sequences, such as Valerie left the birthday party early, She spent an hour shopping at the mall, should not invoke birthday-present knowledge for any reader. However, the data of Table 7 suggest that the small validation effect of the high-span, high-access readers was due to their fast answer times in the control condition, relative to the other groups. This would result if these individuals detected relations between antecedent and outcome in the control sequence that escaped the other readers. For example, readers with spare working memory capacity and efficient knowledge-retrieval mechanisms might process the relatively unlikely possibility that Valerie was shopping for a present after the party. This would result in fast control-condition answer times. Consistent with this interpretation, there is evidence that high-span readers can entertain low-probability interpretations of ambiguous words and syntactic constructions (Just \& Carpenter, 1992; Miyake et al., 1994).

Conversely, the small relation effect of the low-span, low-access readers resulted from their relatively slow answer times in the motive condition. This implies that low-skill readers may focus on lower level language processes, such as lexical access and the construction of propositions. Consistent with this interpretation, constraining subjects to engage in shallow processing, by instructing them to proofread motive-inference sequences, abolishes the validation effect (Singer \& Halldorson, 1996). Superficial processing by readers of low skill is also supported by the finding that skilled and less skilled readers exhibit similar temporal patterns of activation of appropriate words senses, but only the skilled readers exhibit the activation of appropriate topic inferences (Long et al., 1994). A similar analysis may be offered with regard to the distance $\times$ reading span $\times$ access interaction.
Thus, for the interactions under discussion, the covariation of answer times across reading categories resulted in inverted $U$-shaped curves relating effect size (both for relation and distance) and reading skill. That is, it was the heterogeneous reader groups, which might be treated as "mid-skill," that displayed the largest effects. Qualitative processing differences among readers are likely to yield unexpected language comprehension result profiles of this sort. In this regard, Just and Carpenter (1992) addressed the comprehension of sentences such as The experienced soldiers warned about the dangers before the midnight raid. This sentence is ambiguous because, at the point that the verb warned is encountered, it could function as a main verb or as the participle in the reduced relative clause warned about the dangers. Paradoxically, it is only subjects of high reading span who display an ambiguity effect, in the form of elevated reading times for the final word, raid. Just and Carpenter interpreted this to indicate that only the high-span readers maintained both interpretations of the verb as they proceeded through the sentence.

The compensatory view stated that being high in either reading span or access would permit a reader to compute the bridging inferences under inspection. This hypothesis did receive support from the fact that, of the eight motivecontrol comparisons (see Table 6), the smallest was the 40-msec difference detected for low-span, low-access readers in the far condition. However, the relation $\times$ distance $\times$ reading span $\times$ access interaction, which was associated with the compensatory view, did not approach significance. In addition, the second smallest relation effect was detected for the high-span, high-access near condition. This suggests that the answer time pattern is not convincingly captured by the compensatory hypothesis.

It is noteworthy that the relation effect was similar in the near and far inference conditions. This indicates that the four intervening sentences of the far condition did not prohibit the detection of causal connections between motive outcomes and their antecedents. Search for distal motives and causes was not prompted by local incoherence in the texts: In sequences such as She headed north on the freeway, She exited at Antelope Drive, each sentence maintained referential coherence and causally enabled (Schank \& Abelson, 1977) the event of its successor. The appearance of the validation effect in the far inference condition converges with findings, using other procedures, that readers detect causal and spatial relations between both adjacent and nonadjacent sentences in text (Albrecht \& O'Brien, 1993; Klin \& Myers, 1993; O'Brien \& Albrecht, 1992). This outcome is consistent with the proposal that readers have a prevailing goal to identify the causal antecedents of text outcomes (Graesser, Singer, \& Trabasso, 1994). Conversely, it is inconsistent with the minimal inference view that the construction of causal situation models entails a special strategy on the part of the reader (McKoon \& Ratcliff, 1992).

The operation of special strategies for causal processing was examined in another manner. If the subjects' performance in this experiment involved the develop- 
ment of such a strategy, then the relation effect would have been smaller at the outset of practice than it would have been later. However, inspection of the first quarter of experimental trials revealed that motive answer times were $197 \mathrm{msec}$ longer than control answer times. This difference was larger than the overall effect of $152 \mathrm{msec}$, discouraging the special-strategy proposal.

There were few striking features of the reading time and error data. The motive reading time advantage, a familiar effect in this research, is interpreted to indicate that it takes less time to reconcile a text outcome with an antecedent bearing a close causal connection than one with an antecedent bearing a weak causal or temporal connection (Black \& Bern, 1981; Keenan et al., 1984; Myers et al., 1987; Singer, Halldorson, et al., 1992). The robust reading span effect in reading time also merits comment. Previous studies have alternately measured the relationship between reading span and reading time to be negligible (Baddeley et al., 1985, Experiment 1; Singer, Andrusiak, et al., 1992), modest (Dixon et al., 1988), and sizable (Baddeley et al., 1985, Experiment 2). Therefore, firm conclusions about the reading span effect in reading times are premature.

\section{Independent Roles of Working Memory Capacity and Access?}

The relation between working memory capacity and comprehension has received wide attention. We focus, therefore, on the mechanisms whereby access to relevant knowledge promotes successful text understanding. It is proposed, first, that access to relevant knowledge during reading is facilitated by the reader's representation of the situation model underlying a text. Second, it is skilled readers who effectively derive situation models. The implications of this proposal for the independent role of working memory capacity and access will be considered.

Situation models and knowledge access during reading. The situation model is the level of text representation that captures the situation to which a text refers (van Dijk \& Kintsch, 1983; cf. the mental models of Johnson-Laird, 1983). The situation model integrates text ideas and general knowledge in a manner that need not reflect the structure of the original text. One reflection of this integration is that, after reading, text ideas and relevant facts mutually prime one another (McKoon \& Ratcliff, 1988; Potts \& Peterson, 1985; Singer \& Halldorson, 1996).

The construction of an integrated situation model may have a dramatic impact on memory retrieval. One example of this derives from the interference phenomenon known as the fan effect. In this paradigm, people learn unrelated facts, such as The lawyer is in the church. The hippie is in the garage, and The lawyer is in the park (Anderson, 1976). The fundamental finding is that judgment time about related test facts increases systematically with the number of facts learned about both the subject and the predicate of the learned facts. With reference to the latter three facts, it takes longer to decide that The lawyer is in the church was learned than The hippie is in the garage. This is because two facts were learned about the lawyer, but only one fact was learned about the hippie.

When facts in a learned set may be grouped according to themes, such as the circus and skiing, however, a negative fan effect may emerge - that is, answer time is inversely related to the number of facts linked to the test item (Reder \& Anderson, 1980). Reder and Anderson proposed that related facts are integrated into thematic substructures. The eradication of the fan effect is likely attributable to the interconnectedness of the propositions in the structure (McCloskey \& Bigler, 1980; Myers, O'Brien, Balota, \& Toyofuku, 1984; Smith, Adams, \& Schorr, 1978). Although situation models are more frequently thought of as being derived from coherent texts, this construct may be extended to list learning, such as the learning associated with the fan effect paradigm (Radvansky \& Zacks, 1991). The availability of an integrated situation model may provide the reader with efficient access to a complex set of related ideas (Cantor \& Engle, 1993).

The impact of situation models on access to relevant text knowledge is further clarified by Ericcson and Kintsch's (1995) proposal that information stored in specialized long-term structures may be efficiently retrieved by means of cues that reside in the traditional short-term working memory. These long-term structures include ones relevant to mathematical calculation, problem solving, and, most pertinent to the present concerns, situation models derived from text. The coordination of these long-term structures and their retrieval cues amounts to a mechanism that Ericcson and Kintsch termed longterm working memory. Thus, according to Ericcson and Kintsch's analysis, the availability of an integrated situation model effectively extends working memory. In so doing, it enhances the reader's access to antecedent text ideas and to the world knowledge that has become integrated with those ideas.

Situation models and expertise. There is growing consensus that it is reader skill, broadly defined, that promotes the construction of text situation models. Further to their long-term working memory analysis, Ericcson and Kintsch (1995) proposed that the derivation of integrated knowledge structures during complex information processing depends on the expertise of the processor and that this expertise is acquired. With regard to the language realm, this implies that skilled readers can construct integrated and efficient text situation models. As discussed in the previous section, situation models with these qualities enhance the accessibility of their component elements (e.g., Ericcson \& Kintsch, 1995, p. 223).

The analysis of Gernsbacher (1990; Gernsbacher, Varner, \& Faust, 1990) dovetails with this account. Gernsbacher distinguished skilled and less skilled readers in terms of both the efficiency of their language processes and the products of those processes. Inefficient language processes, viewed in this manner, were posited to prohibit the construction of integrated situation models. Instead, Gernsbacher characterized the less skilled reader as shifting frequently from one substructure to another 
and so deriving fragmented, piecemeal representations. A representation of this sort would provide impaired access to text information.

The nature of basic reading skill was considered by Perfetti (1989). He proposed that processes, such as word identification, parsing, and case-role assignment, are generalized abilities. These abilities are independent of domain knowledge, such as knowledge about baseball or biology. Effective reading processes would enable the construction of integrated representations from text in the rapid manner that on-line comprehension demands. That is, the reader, in a short time span, must recognize the words of a message, detect their grammatical organization, extract propositions from these phrases, and relate the propositions to one another and to word knowledge. The ability to accomplish these tasks is a necessary condition for the construction of text situation models.

Distinguishing working memory capacity and access. Evidence suggesting that skilled and less skilled readers differ in their working memory capacity and ease of access to relevant knowledge does not guarantee that these two constructs are distinct. The present data, however, support the independence of working memory capacity and access and identifies their impact on the processes of bridging inference.

Other evidence bearing on the independence of these two reader traits is less direct. Their discriminability would be questioned, for example, by the demonstration that it is, particularly, readers high in working memory efficiency who exhibit superior access to relevant knowledge. Reconsider, therefore, the access differences detected in prior investigations (Gernsbacher, 1990; Long et al., 1994). In neither of these cases was reading skill measured in terms of reading span, the standard measure of working memory efficiency. Gernsbacher measured reading skill using a test battery in which subjects answer questions about stories presented either in writing, auditorily, or in picture form. Long et al. distinguished high- and lowskill readers using the SAT verbal test.

Cantor and Engle (1993), in contrast, documented a relationship between working memory capacity and access. They identified subjects high or low in reading span. The subjects learned sets of facts that could be thematically organized. Like the subjects of Reder and Anderson (1980), the high-span subjects exhibited negative fan effects after learning these materials. The low-span subjects, in contrast, produced the standard fan effect. Consistent with the present analysis of knowledge access, Cantor and Engle concluded that low-span subjects either fail to integrate the thematically related facts or cannot hold an integrated representation in working memory.

The latter outcome works against the independence of working memory capacity and access. However, Ericcson and Kintsch (1995) reinterpreted Cantor and Engle's (1993) findings to indicate that reading span diagnoses not domain-free working memory capacity but rather language processing expertise. In so doing, Ericcson and Kintsch explicitly staked out a strong position-namely, that it is language processing expertise and not generalized working memory capacity that accounts for the relationship between reading span and language comprehension.

It is interesting, therefore, that the capacity-constrained model of comprehension (Just \& Carpenter, 1992) embraces the opposite view - namely, that working memory efficiency is the primary determinant of individual differences among readers. However, as discussed earlier, Just and Carpenter considered alternate working memory capacity and processing efficiency interpretations of the relations between reading span and comprehension. The present treatment raises the possibility that their insight about the distinction between working memory capacity and processing efficiency in reading span is accurate, but that these constructs correspond to two independent determinants of fluent reading.

In contrast with pure capacity and pure expertise positions, our data (see also Singer, Andrusiak, et al., 1992) suggest that the traits of reading span and knowledge make independent contributions to language processing. It is suggestive that other theorists (Daneman \& Carpenter, 1980; Gernsbacher, 1990; Just \& Carpenter, 1992; cf. Ericcson \& Kintsch, 1995) invoked both capacity and process efficiency differences among readers, although they have not treated these characteristics as orthogonal reader traits. The following also strikes us as intuitively appealing: As in all traits, people are likely to vary in cognitive resources and so in working memory capacity. However, there need be no systematic relationship between individuals' working memory capacity and the extent to which they become practiced, efficient readers. Therefore, we consider it likely that ongoing research will converge on the conclusion that knowledge access, the marker of fluent comprehension processes (Gernsbacher, 1990), and working memory capacity make independent contributions to successful comprehension.

\section{REFERENCES}

Albrecht, J. E., \& O'Brien, E. J. (1993). Updating a mental model: Maintaining both local and global coherence. Journal of Experimental Psychology: Learning, Memory, \& Cognition, 19, 1061-1070.

ANDERSON, J. R. (1976). Language, memory, \& thought. Hillsdale, NJ: Erlbaum.

BadDeley, A. D. (1986). Working memory (Oxford Psychology Series, Vol. 11). Oxford: Oxford University Press.

BADDELEY, A. D., \& HiTch, G. (1974). Working memory. In G. H. Bower (Ed.), The psychology of learning and motivation (Vol. 8, pp. 47-90). New York: Academic Press.

Baddeley, A. D., Logie, R., Nimmo-Smith, I., \& Brereton, N. (1985). Components of fluent reading. Journal of Memory \& Language, 24, 119-131

BLACK, J. B., \& BerN, H. (1981). Causal inference and memory for events in narratives. Journal of Verbal Learning \& Verbal Behavior, 20, 267-275.

Bloom, C. P., Fletcher, C. R., van den Broek, P., Reitz, L., \& SHAPIRO, B. P. (1990). An on-line assessment of causal reasoning during comprehension. Memory \& Cognition, 18, 65-71.

CANTOR, J., \& ENGLE, R. W. (1993). Working-memory capacity as long-term memory activation: An individual-differences approach. Journal of Experimental Psychology: Learning, Memory, \& Cognition, 19, 1101-1114. 
Carpenter, P. A., \& Just, M. A. (1989). The role of working memory in language comprehension. In D. Klahr \& K. Kotovsky (Eds.), Complex informational processing: The impact of Herbert A. Simon (pp. 31-68). Hillsdale, NJ: Erlbaum.

Daneman, M., \& CARPENTER, P. A. (1980). Individual differences in working memory and reading. Journal of Verbal Learning \& Verbal Behavior, 19, 450-466.

DANEMAN, M., \& CARPENTER, P. A. (1983). Individual differences in integrating information between and within sentences. Journal of Experimental Psychology: Learning, Memory, \& Cognition, 9, 561-584.

DANEMAN, M., \& TARDIF, T. (1987). Working memory and reading skill re-examined. In M. Coltheart (Ed.), Attention and performance XII (pp. 491-508). London: Erlbaum.

Dixon, P., LeFevre, J., \& TwiLley, L. C. (1988). Word knowledge and working memory as predictors of reading skill. Journal of Educational Psychology, 80, 465-472.

Engle, R. W., Cantor, J., \& Carullo, J. J. (1992). Individual differences in working memory and comprehension: A test of four hypotheses. Journal of Experimental Psychology: Learning, Memory, \& Cognition, 18, 972-992.

ERicCSON, K. A., \& KinTsCH, W. (1995). Long-term working memory Psychological Review, 102, 211-245.

GERNSBACHER, M. A. (1990). Language comprehension as structure building. Hillsdale, NJ: Erlbaum.

Gernsbacher, M. A., VARner, K. R., \& Faust, M. E. (1990). Investigating differences in general comprehension skill. Journal of Experimental Psychology: Learning, Memory, \& Cognition, 16, 430-445.

Glanzer, M., \& Nolan, S. D. (1986). Memory mechanisms in text comprehension. In G. H. Bower (Ed.), The psychology of learning and motivation (Vol. 20, pp. 275-317). San Diego: Academic Press.

Graesser, A. C., Singer, M., \& Trabasso, T. (1994). Constructing inferences during narrative text comprehension. Psychological Review, $101,371-395$

Haviland, S. E., \& Clark, H. H. (1974). What's new? Acquiring new information as a process in comprehension. Journal of Verbal Learning \& Verbal Behavior, 13, 512-521.

JohnSON-LAJRD, P. N. (1983). Mental models. Cambridge, MA: Harvard University Press.

Just, M. A., \& CARPENTER, P. A. (1992). A capacity theory of comprehension: Individual differences in working memory. Psychological Review, 99, 122-149.

Keenan, J. M., Baillet, S. D., \& Brown, P. (1984). The effects of causal cohesion on comprehension and memory. Journal of Verbal Learning \& Verbal Behavior, 23, 115-126.

KLIN, C. M., \& MYERS, J. L. (1993). Reinstatement of causal information during reading. Journal of Experimental Psychology: Learning, Memory, \& Cognition, 19, 554-560.

LeE-Sammons, W. H., \& Whitney, P. (1991). Reading perspectives and memory for text: An individual differences analysis. Journal of Experimental Psychology: Learning, Memory, \& Cognition, 17, 1074-1081.

LONG, D. L., OPPY, B. J., \& SEELY, M. R. (1994). Individual differences in the time course of inferential processing. Journal of Experimental Psychology: Learning, Memory, \& Cognition, 20, 1456-1470

MacDonald, M. C., Just, M. A., \& CARPENTER, P. A. (1992). Working memory constraints on the processing of syntactic ambiguity. Cognitive Psychology, 24, 56-98.

Masson, M. E. J., \& Miller, J. A. (1983). Working memory and individual differences in comprehension and memory of text. Journal of Educational Psychology, 75, 314-318.

MCClosKey, M., \& BigleR, K. (1980). Focused memory search in fact retrieval. Memory \& Cognition, 8, 253-264.

McKoon, G., \& RATCLIFF, R. (1988). Contextually relevant aspects of meaning. Journal of Experimental Psychology: Learning, Memory, \& Cognition, 14, 331-343.

McKoON, G., \& RATCLIFF, R. (1992). Inference during reading. Psychological Review, 99, 440-466.

MilleR, G. A. (1956). The magical number seven, plus or minus two: Some limits on our capacity for processing information. Psychological Review, 63, 81-97.

Miyake, A., Just, M. A., \& Carpenter, P. A. (1994). Working mem- ory constraints on the resolution of lexical ambiguity: Maintaining multiple interpretations in neutral contexts. Journal of Memory \& Language, 33, 175-202.

Myers, J. L., O'Brien, E. J., Balota, D. A., \& Toyofuku, M. (1984). Memory search without interference: The role of integration. Cognitive Psychology, 16, 214-242.

Myers, J. L., SHINJo, M., \& DUfFY, S. A. (1987). Degree of causal relatedness and memory. Journal of Verbal Learning \& Verbal Behavior, 26, 453-465.

O'BRIEN, E. J., \& AlBRECHT, J. E. (1992). Comprehension strategies in the development of a mental model. Journal of Experimental Psychology: Learning, Memory, \& Cognition, 18, 777-784.

Perfetti, C. A. (1989). There are generalized abilities and one of them is reading. In L. Resnick (Ed.), Knowing and learning: Issues for a cognitive science of instruction (pp. 307-335). Hillsdale, NJ: Erlbaum.

Potts, G. R., Keenan, J. M., \& Golding, J. M. (1988). Assessing the occurrence of elaborative inferences: Lexical decision versus naming. Journal of Memory \& Language, 27, 399-415.

Potts, G. R., \& Peterson, S. B. (1985). Incorporation versus compartmentalization in memory for discourse. Journal of Memory \& Language, 24, 107-118.

RadVANSKY, G. A., \& ZaCKs, R. T. (1991). Mental models and the fan effect. Journal of Experimental Psychology: Learning, Memory, \& Cognition, 17, 940-953.

REDER, L. M., \& ANDERSON, J. R. (1980). A partial resolution of the paradox of interference: The role of integrating knowledge. Cognitive Psychology, 12, 447-472.

SChANK, R. C., \& ABElson, R. (1977). Scripts, plans, goals, and understanding. Hillsdale, $\mathrm{NJ}$ : Erlbaum.

SingER, M. (1980). The role of case-filling inferences in the coherence of brief passages. Discourse Processes, 3, 185-201.

SINGER, M. (1993). Causal bridging inferences: Validating consistent and inconsistent sequences. Canadian Journal of Experimental Psychology, 47, 340-359.

Singer, M., ANdrusiak, P., Reisdorf, P., \& Black, N. L. (1992). Individual differences in bridging inference processes. Memory \& Cognition, 20, 539-548.

SiNGER, M., \& FERREIRA, F. (1983). Inferring consequences in story comprehension. Journal of Verbal Learning \& Verbal Behavior, 22, 437-448

Singer, M., Graesser, A. C., \& Trabasso, T. (1994). Global or minimal inference in reading. Journal of Memory \& Language, 33, 421-441.

Singer, M., \& HaLldorson, M. (1996). Constructing and validating motive bridging inferences. Cognitive Psychology, 30, 1-38.

Singer, M., Halldorson, M., Lear, J. C., \& Andrusiak, P. (1992). Validation of causal bridging inferences. Journal of Memory \& Language, 31, 507-524.

Singer, M., Revlin, R., \& HALLDORSON, M. (1990). Bridging-inferences and enthymeme. In A. Graesser \& G. H. Bower (Eds.), The psychology of learning and motivation (Vol. 25, pp. 35-51). New York: Academic Press.

Smith, E. E., Adams, N., \& SCHORR, D. (1978). Fact retrieval and the paradox of interference. Cognitive Psychology, 10, 438-464.

SuH, S., \& Trabasso, T. (1993). Inferences during reading: Converging evidence from discourse analysis, talk-aloud protocols, and recognition priming. Journal of Memory \& Language, 32, 279-300.

TURNER, M. L., \& ENGLE, R. W. (1989). Is working memory capacity task dependent? Journal of Memory \& Language, 28, 127-154.

vaN DiJK, T. A., \& KINTSCH, W. (1983). Strategies of discourse comprehension. New York: Academic Press.

Whitney, P., Ritchie, B. G., \& ClaRK, M. B. (1991). Working-memory capacity and the use of elaborative inferences in text comprehension Discourse Processes, 14, 133-146.

Yuill, N. M., OAKHILl, J. V., \& Parkin, A. J. (1989). Working memory, comprehension ability and the resolution of text anomaly. British Journal of Psychology, 80, 351-361

(Manuscript received June 28, 1995 revision accepted for publication December 2,1995 .) 